\title{
Can practice educators be a 'bridge' between the academy and the practicum?
}

\section{Martyn Higgins ${ }^{1}$}

\begin{abstract}
Debates exist about the separation of the academy and the practicum. The purpose of this study is to explore how its findings may contribute to this discussion. The unique pedagogies of the university and practice are explored and consideration is given to whether practice educators hold an intermediary role. A qualitative study of an undergraduate programme in England using thematic analysis was undertaken once ethical approval was given. Individual interviews and focus groups were used. A total of 48 participants were interviewed at two different points in time (2008 and 2011-2012). Although this is a limited small scale study not susceptible to generalisation it may be able to provide an analytic generalisation, which may be replicable with further studies.

The findings indicated practice educators struggled to act as a bridge because the academy and the practicum have conflicting and competing signature pedagogies. The contribution of this study is to the contemporary discussion on the SWRB changes and models such as Frontline.
\end{abstract}

Keywords: signature pedagogies; practice educators; social work education; SWRB; Frontline

\section{Principal Lecturer, London South Bank University}

Address for correspondence: Faculty of Health and Social Care, London South Bank University 103 Borough Road London SE1 OAA. higginm2@lsbu.ac.uk

Date of first (online) publication: 16th May 2014

62 J. of Practice Teaching \& Learning 12(3), pp.62-78. DOI: 10.1921/7802120301. @ wEbb 2014 


\section{Introduction}

The debates about the gulf or separation between the academy and the practicum are common in social work literature. Various analyses and solutions have been proffered over the years. This study is different because its focus is on the pedagogies of the university and practice and links these approaches to learning to practice educators. Using the model of 'signature pedagogies' in relationship to the role of practice educators, the paper argues that practice educators find it difficult to act as intermediaries because the academy and the practicum have conflicting and competing signature pedagogies. It is hoped that the study may contribute (within the limitations of the study) to current discussions about the future of social work education. What students learn is what they implement in practice (Shulman, 2005).

\section{Background}

Despite the importance of practice learning, research tends to be limited (Parker, 2007). Where there are studies of practice, research tends to centre on social work academics and students rather than those responsible for assessing practice (Moriarty et al., 2010). This paper provides an opportunity to review the debates about the relationship of the university and practice by exploring how the role of the practice educator may illuminate these discussions.

The model of 'signature pedagogies' is adopted as providing an innovatory way to approach the question of the academy/practicum relationship and the role of practice educators. Shulman (2005) developed the concept as a way of describing and identifying the typical features of different professions. Although the signature features of medicine may be different from those of engineering, they could be grouped within three fundamental categories: thinking, doing and ethical integrity. How these three dimensions are expressed will vary from profession to profession.

There has been limited use of the signature pedagogy model in social work and mainly confined to North America (Wayne et al., 2010; Larrison and Korr, 2013). The importance of ethical integrity as part of a profession's signature pedagogy is particularly apposite in the current state of professions in England. The Munro Review (Munro, 2011) into child

63 J. of Practice Teaching \& Learning 12(3), pp.62-78. DOI: 10.1921/7802120301. @ w\&b 2014 
protection in social work and the Mid Staffs Inquiry (Francis, 2013) into nursing practice within a hospital are examples where there was concern that professionals had lost their sense of ethical integrity.

The Munro Review was set up to review the current state of child protection in England. The review adopts similar recommendations to that of the Social Work Reform Board (SWRB) discussed below. They each identified serious weaknesses in existing social work education and practice. Social workers need to move away from a process-driven practice and a culture of blame and 'reclaim' their professional expertise. Munro in particular emphasised the learning cultures of statutory agencies and the need for a learning culture to be at the heart of statutory agencies.

Most important of all in the present climate of social work in England is the centrality of pedagogy. Within a signature pedagogy approach learning, knowledge and values are central to understanding the key features of a profession. Social work education is currently undergoing significant alterations. The SWRB was established to implement changes to social work education and practice (Social Work Task Force, 2009) following the death of Peter Connelly (Haringey Local Safeguarding Board, 2009). The SWRB's changes to qualifying practice have introduced major alterations to social work education (Social Work Reform Board, 2011).

Other proposed changes to social work education such as Frontline (MacAlister, J. with others, 2012) also bring to the fore the centrality of pedagogy in qualifying training. Frontline was introduced to provide a better quality of training and education to social work students. Students undertake a shortened period of training (13 months instead of standard 24 months on normal MA social work programmes) within a placement where 50 days of education and training are delivered within the organisation. A systemic approach to social work practice is adopted throughout the programme.

This study is centred on exploring the role of practice educators within the academy/practicum relationship. However, its focus on the pedagogies of the university and practice is connected to wider contemporary changes such as the SWRB reforms and such projects as Frontline. A profession can best be understood by the way in which its students are educated (Shulman, 2005).

There is a relatively extensive literature on the tensions and contrasting approaches of the academy and the practicum in social work literature (Randall, 2002; Green, 2006; Humphrey, 2006; Delaney, 2007; House of Commons Children, Schools and Families Committee, 2009; Jack and

64 J. of Practice Teaching \& Learning 12(3), pp.62-78. DOI: 10.1921/7802120301. @ wEb 2014 
Donnellan, 2009; Singh and Cowden, 2009; Preston-Shoot, 2012; House of Commons Children, Schools and Families Committee, 2009; All Party Parliamentary Group on Social Work, 2013; Social Work Action Network, 2014).

There appears to be a 'chasm' (Humphrey, 2006, p. 372) between the conceptual and ethical approach of the university and the process and performance base of practice. Newly qualified social workers soon discover that employers are not interested in their personal and professional development, but only on their ability to reach their targets (Jack and Donnellan, 2009). One former student (Delaney, 2007) referred to the 'dichotomy' between the theory taught in the academy and the realities of practice in a children's family and assessment team. There were at times tensions between the demands of practice and the ethical base of the profession. Following procedures often took precedence over social work ethical practice. Social workers were expected to do things right or follow procedures rather than do the right thing or help children (Munro, 2011). One House of Commons committee stated there was a 'gulf in understanding between the employers and social work educators' (House of Commons Children, Schools and Families Committee 2009, p. 11).

This study aims to review the role of practice educators within the wider context of social work reform and the existing tensions between the academy and the practicum.

\section{Methodology}

The present paper is derived from a larger case study of an undergraduate social work programme in England (Higgins, 2013). An undergraduate programme was chosen because the social work qualification in England is set at undergraduate level. Students who hold an existing degree will normally undertake a two-year MA. Such students will normally be older and may have more relevant experience than undergraduate students. If a MA programme had been chosen it is possible the results would have been different. A qualitative case study using thematic analysis (Braun and Clarke, 2006) was undertaken once ethical approval was given. Individual interviews and focus groups were used.

A hermeneutic strategy was adopted (Ansells, 1996). The degree was chosen as the starting point or lens in order to investigate the whole or

65 J. of Practice Teaching \& Learning 12(3), pp.62-78. DOI: 10.1921/7802120301. @ wEb 2014 
wider context of contemporary social work. A number of contradictions or dichotomies were identified within the degree which tended to reflect existing dilemmas or tensions within social work practice. This is a small-scale qualitative study not susceptible to generalisation. However, it may provide an analytic generalisation (Yin, 2009), which may provide opportunity to develop a testable hypothesis for further research.

A total of 48 participants were interviewed at two different points in time (2008 and 2011-2012). There were individual interviews with academics $(n=10)$, practice learning leads based within the university programme $(n=2)$ and practice educators $(n=8)$. There were 3 student focus groups $(n=17)$ and two service user focus groups $(\mathrm{n}=11)$. Although this is a limited small scale study not susceptible to generalisation it may be able to provide an analytic generalisation (Yin, 2009), which may be replicable with further studies. A more detailed explanation of the methodology will be provided in a later article.

\section{Findings}

\section{The signature pedagogy of the university}

Participants saw the replacement of the Diploma in Social Work with the social work degree as a radical change in social work education. The introduction of the degree may indicate the key features of degree level social work pedagogy (Shulman, 2005). Whereas at diploma level the learning model was more like an apprenticeship, the degree made students want to intervene to bring about changes and resolve problems. Successful practice at degree level required more than being able to complete tasks. The social work degree expected students to think for themselves and make sense of problems by using theory:

I suppose that one way to describe the difference between diploma level and degree level, or below diploma almost, is a bit like an apprenticeship model where you tell people how to perform tasks and they do it. Whereas to be truly professional, don't you want people who can change and solve problems? And to have that they need the theory base from which to act. (A4 L255-260)

It was not simply the learning that was different in the degree. The

66 J. of Practice Teaching \& Learning 12(3), pp.62-78. DOI: 10.1921/7802120301. @ w\&b 2014 
type of knowledge was also particular to the pedagogy of the university. The knowledge students acquired could enable them to conceptualise their interventions from their understanding of theories. The pedagogic underpinning of this knowledge was that it could provide an explanatory way to inform and guide the students' work with service users. Students were encouraged to reflect and consider which methods and theories would be helpful in a given situation:

I think theory is used in social work to help the students be very clear about what particular methods, theories that they're using when they're working with the service user, and it's a body of knowledge that they're able to draw on which can underpin their work. (PE4 L303-306)

The university encouraged students to question critically and not simply accept what they were told. Students had to reach their own decisions with the use of theory and knowledge. Students should question and make up their own minds in a critical evaluation of the issues:

I think we teach people to challenge, we teach people to question, we teach people to think and critique. (A9 L109-110)

This approach to learning could be seen as developmental because students had to learn to think critically. Students started by acquiring knowledge of theories and ideas. After which they learnt to assess what they had learnt critically:

Helping the students to go almost incrementally from beginning to understand concepts and ideas and contexts through to more beginning to kind of evaluate and critically evaluate. (A6 L153-155)

Fundamentally the signature pedagogy of the university was to make social work students think more critically and not be trained to perform well:

You train somebody for the Olympics to run fast and educate somebody to think better'. (A9 L813-814)

67 J. of Practice Teaching \& Learning 12(3), pp.62-78. DOI: 10.1921/7802120301. @ w\&b 2014 


\section{The signature pedagogy of statutory social work settings}

Many participants thought a statutory type placement was essential for students because it prepared them for practice (1SFG3 L37-39). When students were not in statutory settings they felt that they were out of place or not obtaining the experience they required. There seemed to be no social work role in placements that were not statutory:

It was a voluntary sector after school project in south [name of city] and I was doing a lot of [pause] I'm not going to lie, the majority of the time I felt like an unpaid play worker for 100 days. And I really, really did not like it. I didn't feel I was benefitting from it at all; I almost didn't want to finish. (3SFG5 L667-670)

In statutory settings students learnt to develop their skills, which centred on knowing what to do, understanding the law and keeping to timescales. Any involvement with service users was limited because the main work was on completing forms:

When intervention comes about it's very much about fitting in a certain bureaucratic guidance about when you intervene. (A1 L454-456)

It was not always clear what 'statutory' placements were. However, the focus in statutory placements seemed to be on obtaining set goals rather than the nature of the direct work with service user. Practice was limited to a narrow focus on undertaking assessments in a superficial way, which lacked depth:

If more and more social work gets defined as the very narrow role of completing an initial assessment form, gathering information and then making the basis, making the decision on the basis of specific criteria, to whether it goes in this direction or that direction, or whether you commission services and make recommendations or referrals on. Well, if that's done in a very minimalist, superficial way, which I think it is increasingly, given the timescales people are given to do that work, that dictates a minimalist intervention, approach; then anybody could do that. Anybody who could read and write and ask questions. So I think I would be worried about the way social work is going. (A6 L416-423)

There seemed to be an absence of an ethical engagement (Doel et al, 2010), or, worse, a contradiction between the values taught at university

68 J. of Practice Teaching \& Learning 12(3), pp.62-78. DOI: 10.1921/7802120301. @ w\&b 2014 
and encouraged in practice. One student related how he tried to calm an irate service user by informing him of his right to complain. The student felt this would reduce the tension and promote the empowerment of the service user. A few days later the service user's social worker approached the student and informed him that service users were not encouraged to make complaints (1SFG1 L377-381). Despite the 'rhetoric' (A3 L38-46) students found that they could not put their values and ambitions into practice because the work they undertook and the expectations of their organisations were inimical to an ethical practice. Students became subject to a 'slow disillusionment' (A2 L442-443). Having entered the profession and been encouraged at university to put into place their desires to help others and challenge oppression, in practice they found they were sitting at computers and filling in forms:

They come in as very idealistic and want to change the world, help people, support people, solve social ills, wanting to solve people's problems. And they go out there and they are just in situations where they are just processing [pauses] problems in a very bureaucratic way. (A2 L270-274)

\section{The role of the practice educator}

The previous two themes indicated that the signature pedagogies of the academy and the practicum were not only opposed to each other but, also, were offering competing models or approaches for students. The final theme considers to what extent practice educators can reconcile these differences between the university and practice. There was certainly evidence to suggest practice educators were understood as a 'bridge' (Al L402-407) between the two distinct systems. In some sense practice educators were the connection between the academy and the practicum. This bridging role could also be described as a 'link' or connection between the academy and the practicum:

As the practice educator my link with the university is the tutor, and I see the tutor as there to support the student and being also there for me if I'm having [pause] and also for the student, if that partnership that we have isn't working. (PE4 L453-455)

However, the use of the metaphor of practice educator as a bridge also reinforced the sense of a gulf or gap between the two organisations:

69 J. of Practice Teaching \& Learning 12(3), pp.62-78. DOI: 10.1921/7802120301. @ w\&b 2014 
There's clearly a gap between the actual experience of practice for social workers and what they do in the reality of practice and what social workers are taught in the university. (A1 L402-407)

There seemed to be a limited connection between practice educators and tutors. Practice educators and tutors tended not work together to support student learning:

When you've got a student on placement with you, the interaction and the networking between university and placement is confined to a midway meeting. There isn't much sense of joining together to oversee the student's experiences. (PE7 L419-423).

The question is: how can practice educators bridge the gulf between the university and practice? The findings tended to indicate two important problems which inhibited the bridging or intermediary role of practice educators. The first difficulty was that practice educators themselves felt uncomfortable with the signature pedagogy of the academy. Practice educators were in fact 'frightened' of the academic pedagogy:

I have to say when I teach on practice educator courses the one thing that's always the fear of the practice educators is enabling students to link theories to practice. And I think that stems from the fact that people work without consciously or with knowing why they do things and knowing what is their evidence base for what they're doing and their theoretical context. So that's why I think they're frightened of it. (B1 L460-465)

When practice educators undertook training to prepare for students, they struggled to understand how to help students connect theory (the signature pedagogy of the academy) with practice. Practice educators did not make use of theory in practice. If practice educators did not know why they undertook certain interventions, it was unclear how they could enable students to transfer the learning from the pedagogy of the university to the practice setting.

The second problem for the notion of practice educators as links or bridges between the university and practice was that practice educators were in reality inculcated into the signature pedagogy of the practicum and could not be seen as intermediaries between the dissonant fields of the academy and the practicum. Further, it may be argued that practice educators were afraid of the signature pedagogy of the university precisely

70 J. of Practice Teaching \& Learning 12(3), pp.62-78. DOI: 10.1921/7802120301. @ wEb 2014 
because they themselves thought and acted within the signature pedagogy of the practicum. Practice educators informed students that the learning and approach of the university was not needed in practice:

That's college stuff, that's book stuff. You can leave that all behind now.' We have practice educators that openly say that to students in their first week of induction. 'College stuff you can forget about for now. That's all book stuff.' It may say a lot about our profession and where it places itself in terms of academic and practice. (A6 L310-313)

What was interesting about the phrasing of the contrast in the above quotation was the comparison of the university or college with books and reading. It might be said that reading could be seen as part of the signature pedagogy of the university. Once students were on placement, they no longer needed to learn. Students simply had to perform or undertake activities without recourse to learning acquired from theory or texts. In fact, reading was seen as a negative feature for practitioners too. Reading in work indicated social workers did not have enough work or were looking for other jobs:

'If you're seen reading something you obviously need another case, or you're looking for another job'. (B1 L461-463)

The problematic nature of the role of practice educators as a bridge or intermediary was the result of a core tension between pedagogies. There was a conflict between the academy and the practicum in terms of their signature pedagogies. Practice educators were part of the pedagogy of practice. Practice educators were not caught between two opposing sides: they were on the side of practice.

It was evident in the findings that there was a problem with the different signature pedagogies of the academy and the practicum. It was in a sense a 'struggle' between different ways of thinking, doing and ethical values:

What we always struggle with in social work is that, you know, we've got the practice placement over there and the university is over here. It's seen as a very separate entity and the students get their practice experience in one place and the theory in another. (A5 L810-813)

71 J. of Practice Teaching \& Learning 12(3), pp.62-78. DOI: 10.1921/7802120301. @ wEb 2014 


\section{Discussion}

There is nothing new about a gap or difference between the academy and field education in social work (Parker, 2007; Rodie, 2008; Woodward and Mackay, 2012). There has been also some limited discussion of the relevance of signature pedagogies to social work (Wayne et al., 2010; Larrison and Korr, 2013). What distinguishes this study from others is that it indicates that practice educators struggle to act as intermediaries between the university and practice. The key message is that practice educators find it difficult to act as a bridge because the academy and the practicum have conflicting and competing 'signature pedagogies'.

Some writers suggest that the contradictions between the university and practice can be resolved by integrating (Wilson and Kelly, 2010) or dissolving the difference between the academy and the practicum (Singh and Cowden, 2009). Others recommend models of joint working across the divide between the university and practice (Skinner and Whyte, 2006). What distinguishes this study is that it argues that the signature pedagogies are oppositional and competing.

The present state of social work is one of distinct tracks (Spours et al, 2000) going in opposing directions (Preston-Shoot, 2012). Models of the relationship between the academy and the practicum may be divided into three approaches (Spours et al., 2000). The first model is a 'tracked' system within which there are distinct and separate 'tracks' or pathways. There is a 'linked' system within which there are shared or common features which link or connect the different tracks. Thirdly, there is a 'unified' model, which eliminates tracks and brings together the different parts within a unified system. The present state of social work in England has a tracked model. Students spend part of their time in university and 170 days in practice. There are now 30 skills days, which may improve the connection between the two pedagogies. The problem identified in this study is not the tracked model. The principal issue is that the two sides do not share an underlying pedagogy or model of teaching and learning. While the university provides a developmental approach and a critical engagement with learning, practice focusses on getting work done and questioning and criticism are not encouraged (Preston-Shoot, 2012). The 'reality shock' of practice when students qualify starkly contrasts these competing pedagogies (Jack and Donnellan, 2010, p. 309).

The importance of ethics and the application of professional values to practice are not at times evidenced in practice. One study used vignettes

72 J. of Practice Teaching \& Learning 12(3), pp.62-78. DOI: 10.1921/7802120301. @ w\&b 2014 
to explore professionals' reaction to violation of professional boundaries. There was no discussion of human rights and limited reference to regulatory or professional codes of practice (Doel et al., 2010). There is a dichotomy (Delaney, 2007) between the education of social workers and the realities of practice. A study of the use of professional knowledge and research in adult social services found that social workers were influenced in their practice not by professional knowledge but by procedures and targets (McDonald et al., 2008). There existed 'different cultures and... different language' (McDonald et al., 2008, p. 105).The values and knowledge taught within the academy were difficult to apply in organisational settings which were not interested in ethics and expertise (Preston-Shoot, 2012).

It may be contended that the implementation of the SWRB reforms from 2013 have resolved this dichotomy (Delaney, 2007). In particular the introduction of the Professional Capabilities Framework (PCF) has produced an integrated or, at least, developmental, model of learning and knowledge, which can be used both in the academy and the practicum. It is certainly true that the PCF appears to have more in common with such broad conceptions of social work such as the International Federation of Social Work (2000) and the Quality Assurance Agency Benchmark Statement for Social Work (2008). Other innovations such as the introduction of the practice educator professional standards (PEPS) may indicate a determination to use practice educators to bridge the gulf between practice and the university (The College of Social Work, 2013). The standards are mapped against the PCF, which has an underlying developmental and professional focus. Whether the PCF and the PEPS alone can transform the existing divide may be doubtful but it is evidence of a commitment to 'reclaiming' social work for the profession.

There is a danger that encouraging reforms such as the PCF and the PEPS may not herald a shift in the tensions between the signature pedagogies of the academy and the practicum. It is important to be aware of the risk of a 'transformational rhetoric' (Garrett, 2012) in the current spate of reforms. The language of transformation in the idea of 'reclaiming' social work may be only a way of reframing the dominance of the signature pedagogy of statutory work within a more attractive outer wrapping. An example of this may be seen in Frontline (MacAlister with others, 2012) the structure of which was considered above in the background section. It may be argued that Frontline provides a 'unified' system (Spours et al., 2000),

73 J. of Practice Teaching \& Learning 12(3), pp.62-78. DOI: 10.1921/7802120301. @ w\&b 2014 
which integrates and reconciles the tensions between the existing divide of academy and practicum. On the surface it appears to offer a positive solution to the dichotomy considered in this paper. However, there are a number of concerns, which may indicate that the rhetoric of Frontline disguises an attempt to reduce social work to a single type of pedagogy identified in the findings of this research as statutory social work. There are three indications that tend to support this criticism of Frontline. First, the 13 month programme includes only 50 days of education and training. Second, the training is very much within a child protection model. Finally, a systems approach is adopted in the training. These features clearly appear to limit social work to a matter of child protection, a narrow training and only one model of intervention. Frontline may have much to offer but it seems to lead to a version of social work, which runs the risk of losing a wider conception of the profession, found in the signature pedagogy of the academy. A unitary pedagogy may be created, which mirrors the signature pedagogy of statutory social work.

It remains to be seen whether the PCF and the SWRB changes will resolve the gulf or dichotomy between the academy and the practicum (Preston-Shoot, 2012; Higgins, forthcoming). Arguably the tensions between the university and practice may also be understood to be a reflection of a struggle (Singh and Cowden, 2009) between competing models of social work (Preston-Shoot, 2012; Higgins, 2013). Whether the changes of the SWRB will resolve these dilemmas remains to be seen (Garrett, 2012; Preston-Shoot, 2012). However, the fact that social workers continue to report that social work practice is dominated by bureaucracy and a blame culture may indicate that reclaiming social work has yet to be evidenced sufficiently on the frontline (All Party Parliamentary Group on Social Work, 2013).

\section{Recommendations}

The key message of this study is that practice educators find it difficult to act as a bridge because the academy and the practicum have conflicting and competing 'signature pedagogies'. What is required in addition to such reforms as the PCF and PEPS is a strategic and comprehensive engagement with both social work education and practice (Randall, 2002). Being a 'bridge-builder' will necessitate a radical and transformative change in

74 J. of Practice Teaching \& Learning 12(3), pp.62-78. DOI: 10.1921/7802120301. @ wEb 2014 
social work. Randall (2002) makes the key point that bridges are built for two lanes of traffic. Practice educators will need a model or approach that can straddle the two pedagogies and encourage both sides to cross and re-cross the bridge.

The subject at the centre of this study is the nature and function of pedagogy and, in particular, the role of the practice educator. The findings from the current study are limited and are not generalisable. Nonetheless they are consistent with a number of existing studies. A possible way forward for practice educators and the social work professional community (educators and practitioners) may be to reposition the question of pedagogy as the starting point for a radical challenge to the conflict of the existing pedagogies of the university and practice. Green (2006) and Singh and Cowden (2009) argue that it is our understanding of pedagogy that needs to be revisited. One way forward is to argue that what is required is a critical pedagogy to replace the current competing pedagogies of the university and practice.

Critical pedagogy challenges the divide (Singh and Cowden, 2009) between education and practice. It acknowledges also the importance of moving beyond the academy (Green, 2006; Singh and Cowden, 2009). What distinguishes critical pedagogy from other approaches is that is envisions pedagogy as political and politics as pedagogical (Giroux, 2011). Academics have to realise that learning itself is part and parcel of society and the political good or telos of the state. Practitioners, policy makers and politicians must learn that the art of politics or getting things done is about teaching and learning.

Practice educators will have to learn to be both educators and politicians, if they are to lead the profession beyond the competing models of existing social work. It is an arduous and dangerous journey but it is a possible and visionary path. However, critical pedagogy challenges the whole of the profession to support practice educators in becoming critical pedagogues. The reforms to social work education such as the PCF, PEP and the College of Social Work have created the tools to develop a critical pedagogy. Becoming involved in critically engaged organisations such as the Social Work Action Network (2014) will also enable the development of a critical pedagogy.

75 J. of Practice Teaching \& Learning 12(3), pp.62-78. DOI: 10.1921/7802120301. @ w\&b 2014 


\section{References}

All Party Parliamentary Group on Social Work (2013) Inquiry into the state of social work report. Birmingham: British Association of Social Work

Ansells, M. (1996) Hermeneutic phenomenology: philosophical perspectives and current use in nursing research. Journal of Advanced Nursing. 23, 4, 705-713

Braun V. and Clarke V., (2006) Using thematic analysis in psychology. Qualitative Research in Psychology, 3, 77-101

The College of Social Work (2013) Practice educator professional standards and guidance. Available at: http://www.tcsw.org.uk/uploadedFiles/TheCollege/ Social_Work_Education/PEP\%20standardsand\%20guidance\%20update\%20 proofed\%20and\%20final\%20021213.pdf [Accessed: 08/02/14]

Delaney, P., E. (2007) The dichotomy of theory and practice: ethical reflections of a third-year student's placement experience. Ethics and Social Welfare, 1, 1, 108-110 Doel, M., Allmark, P., Conway, C., Cowburn, M., Flynn, M., Nelson, P., and Tod, A, (2010) Professional boundaries: Crossing a line or entering the shadows? British Journal of Social Work, 40, 1866-1889. Advance Access publication October 14, 2009

Eraut, M. (1994) Developing Professional Knowledge and Competence. London: RoutledgeFalmer

Francis, R. (2013) Report of the Mid-Staffordshire NHS Foundation Trust public inquiry. Available at: http://www.midstaffsinquiry.com/assets/docs/Inquiry_Report-Voll. pdf [Accessed 06/02/13]

Garrett, M. (2012) Re-enchanting social work? The emerging 'spirit' of social work in an age of economic crisis. British Journal of Social Work, pp.1-19. DOI: 10.1093/ bjsw/bcs146. Advance Access published October 11, 2012

Giroux, H., A., (2011) On critical pedagogy. London: Continuum

Green, L. C. (2006) Pariah profession, debased discipline? An analysis of social work's low academic status and the possibilities for change, Social Work Education, 25. 3. $245-264$

Haringey Local Safeguarding Board (2009) Serious Case Review: Baby Peter. Executive summary. Available at: http://www.haringeylscb.org/executive_summary_peter_ final.pdf [Accessed: 12/09/12]

Higgins, M. (2013) The dilemmas of contemporary social work: a case study of the social work degree. A thesis submitted in partial fulfilment of the requirements of London South Bank University for the degree of Doctor of Philosophy, July 2013

Higgins, M. and Goodyer, A. (2014)The Contradictions of Contemporary Social Work: An Ironic Response, British Journal of Social Work, pp. 1-14 doi:10.1093/ bjsw/bcu019

76 J. of Practice Teaching \& Learning 12(3), pp.62-78. DOI: 10.1921/7802120301. @ w\&b 2014 
House of Commons Children, Schools and Families Committee (2009) Training of Children and Families Social Workers. Seventh report of session 2008-09. Volume 1. London: The Stationery Office

Humphrey, C. (2006) Tomorrow's social workers in the UK. European Journal of Social Work, 9, 3, 357-373

International Federation of Social Workers (2000) available at: http://www.ifsw. org/f38000138.html Accessed: 5/08/11

Jack, G. and Donnellan, H. (2010) Recognising the person within the developing professional: Tracking the early careers of newly qualified child care social workers in three local authorities in England,. Social Work Education, 29, 3, 305-318

Larrison, T., E. and Korr, W., S. (2013) Does social work have a signature pedagogy? Journal of Social Work Education, 49, 194-206

MacAlister, J. with Crehan, L. and Olsen, A. (2012) Front line: Improving the children's social work profession. Available at: http://www.nccesb.org.uk/pdfs/publicationfrontline-childrens-social-work_Oct2012_9705.pdf [Accessed: 20/10/12]

Moriarty J., MacIntyre, G., Manthorpe, J., Crisp, B., R., Orme, J., Green Lister, P., Cavanagh, K., Stevens, M., Shereen Hussein, S. and Sharpe, E. (2010) 'My expectations remain the same. The student has to be competent to practise': practice assessor perspectives on the new social work degree qualification in England, British Journal of Social Work, 40, 583-601. Advance Access publication 19/01/09

Munro, E. (2011) Review of Child Protection: Final Report (2011). Available at: http:// www.education.gov.uk/munroreview/ [Accessed 22/07/11]

Parker, J. (2007) Developing effective practice learning for tomorrow's social workers. Social Work Education, 26, 8, 763-779

Parsloe, P. (2001) Looking back on social work education. Social Work Education, 20, 1, 9-19

Quality Assurance Agency (2008) Benchmark statement for social work. Available at: http://www.qaa.ac.uk/Publications/InformationAndGuidance/Documents/ socialwork08.pdf [Accessed: 27/07/12]

Randall, J. (2002) The practice-research relationship: a case of ambivalent attachment? Journal of Social Work, 2, 1, 105-122

Rodie, S. (2008) Whistleblowing by students in practice learning setting: the student perspective. Ethics and Social Welfare, 2, 1, 95-99

Sainsbury, E. (1977) The Personal Social Services. London: Pitman

Shulman, L.S. (2005). Signature pedagogies in the professions. Daedalus, 134, 3, 52-59

Singh, G. And Cowden, S. (2009) The social worker as intellectual. European Journal of Social Work, 31, 3, 1-15

77 J. of Practice Teaching \& Learning 12(3), pp.62-78. DOI: 10.1921/7802120301. @ w\&bb 2014 
Social Work Action Network (2014) In Defence of Social Work: why Michael Gove is wrong

Social Work Reform Board (2011) Building a Safe and Confident Future: Improving the quality and consistency of initial qualifying social work education and training. Available at: http://www.collegeofsocialwork.org/uploadedFiles/TheCollege/ Practice/Improving\%20the\%20quality\%20and\%20consistency\%20of\%20 initial\%20qualifying\%20social\%20work\%20education\%20and\%20training. pdf [Accessed 06/12/12]

Social Work Task Force (2009) Building a Safe, Confident Future: The final report of the Social Work Task Force. Available at:https://www.education.gov.uk/publications/ eOrderingDownload/01114-2009DOM-EN.pdf [Accessed: 09/06/12]

Spours, K., Young, M., Howieson, C. and Raffe, D. (2000) Skills development in higher education and employment. in F. Coffield (Ed) Differing Visions of a Learning Society. Bristol: Policy Press

Wayne, J., Bogo, M., and Raskin, M. (2010). Field education as the signature pedagogy of social work education: congruence and disparity. Journal of Social Work Education, 46, 327-339

Wilson, G. and Kelly, B. (2010) Evaluating the effectiveness of social work education: preparing students for practice learning, British Journal of Social Work, 40, pp. 2431-2449. Advance Access publication February 23, 2010

Woodward, R. and Mackay, K. (2012) Mind the gap! Students' understanding and applications of social work values, Social Work Education, 31, 8, 1090-1104 Yin, R., K. (2009), Case Study Research. (4th ed.) London: Sage

78 J. of Practice Teaching \& Learning 12(3), pp.62-78. DOI: 10.1921/7802120301. @ wEb 2014 